\title{
Natural Co-Occurrence of Aflatoxins, Cyclopiazonic Acid, and their Production by Aspergillus Flavus Isolates from Corn Grown in Egypt
}

\author{
Deabes MMY1*, Amra HA ${ }^{1}$, Damaty ELM${ }^{2}$ and Rowayshed GH² \\ 1Food Toxicology and Contaminants Department, National Research Centre, Cairo, \\ Egypt \\ ${ }^{2}$ Food Science and Technology Department, Faculty of Agriculture, Al-Azhar University, \\ Cairo, Egypt
}

${ }^{*}$ Corresponding author: Mohamed M Deabes, Food Toxicology and Contaminants Department, National Research Centre, 33-El Bohouth street-Dokki, Cairo, 12311, Egypt, Email: mydeabes@yahoo.com

\section{Abstract}

Mycotoxins are metabolites of fungi that can adversely affect animal and human health. Mycotoxins can be produced in corn during storage or processing, but are most frequently associated with fungal infection that occur before harvest. Sixty corn samples were purchased from retail markets from Cairo and Giza Governorates in summer and winter seasons from Egypt. The samples were examined for dominants fungi and mycotoxins Aflatoxins (AFS) and cyclopiazonic acid (CPA) and their Aspergillus flavus production. AFS and CPA were determined by high performance liquid chromatography (HPLC). The results indicated that, the dominants fungi genra were Aspergillus, Fusarium, Penicillium and Alternaria in all corn samples in summer and winter seasons. From 239 of Aspergillus genus isolates 63.7\% was identified as A. flavus, they were tested for AFS and CPA production. The results were showed that only 96 out from 151 A. flavus isolates (63.6\%) were positive to AFS and CPA toxins production. The results indicated that $64.6 \%$ from A. flavus isolates were produced both of AFS and CPA. The averages of AFS and CPA production were 9.4 and $12.56 \mathrm{mg} / \mathrm{L}$ in YES medium respectively. For natural co-occurrence of AFS and CPA in corn samples, the results indicated that 9 samples out from 30 $(30.0 \%)$ and $7 / 30$ (23.3\%) from corn grain samples collected from Cairo Governorate in winter season were contaminated with both of AFS $\left(B_{1}, B_{2}, G_{1}\right.$ and $\left.G_{2}\right)$ and CPA, respectively. On the other hand, in summer season 11 samples out from $30(36.3 \%)$ and 8/30 (26.6\%) were contaminated with both of AFS $\left(\mathrm{B}_{1}, \mathrm{~B}_{2}, \mathrm{G}_{1}\right.$ and $\left.\mathrm{G}_{2}\right)$ and CPA, respectively. The results also indicated that 7 out from 30 (23.3\%) and 6/30(20\%) of corn samples collected from Giza Governorate were contaminated with AFs and CPA respectively in winter season. While, 10 samples out from 30 (33.3 \%) and 10/30 (33.3\%) samples were contaminated with AFS and CPA in Giza Governorate in summer season respectively. These represent $23.3 \%$ and $33.3 \%$ AFS positive samples for corn grain samples collected from Giza Governorate in both season. The concentration of both AFS $\left(B_{1}, B_{2}, G_{1}\right.$ and $\left.G_{2}\right)$ and CPA were ranged from (0.93 -45.5, 0.10- 19.0, 0.20-23.0 and 
0.22-18.0) and 1.2-56.0 $\mu \mathrm{g} / \mathrm{kg}$ in the corn samples were collected from Cairo and Giza Governorates in summer and winter seasons respectively. Our study try to resolve this problem by modification a novel incubating the CPA spots detection with indirect apparel color reagent which giving stable spots color on TLC an obvious detection and an accurate quantitative determination by using the densitometric procedure. This is the first report of natural co-occurrence of $\mathrm{AFs}$ and CPA and there fungi production in Egypt.

Keywords: Aflatoxins; Cyclopiazonic Acid; Fungi; Aspergillus Flavus; HPLC; TLC

Abbreviations: AFS: Aflatoxins; CPA: Cyclopiazonic Acid; HPLC: High Performance Liquid Chromatography; TLC: Thin Layer Chromatography.

\section{Introduction}

Mycotoxins are secondary metabolites produced by specific filamentous fungi that contaminate agricultural commodities. They are toxic to humans and animals, cause significant reductions in crop yield and cause economic losses [1,2]. Their occurrence in various countries has been well documented [3]. A number of fungal species associated with corn, belonging mainly to the genera Aspergillus, Fusarium and Penicillium, have been reported to produce Mycotoxin [4]. Aspergillus flavus and Aspergillus parasiticus are important contaminants of certain foods and animal feeds because of their ability to produce Aflatoxins [5]. When these fungi invade and grow in commodities such as peanuts, corn and cottonseed, the resulting contamination with Aflatoxins often makes the commodities unfit for consumption [6]. Maize is ranked second to wheat among the world cereal crops and is often invaded before harvest by $A$. flavus and $A$. parasiticus that produc mycotoxins [8]. Aflatoxins are considered the most carcinogenic, mutagenic, teratogenic, cytotoxicity and genotoxicity, substances found naturally in foods and feeds [7-9]. These metabolites cause liver damage to humans and to most experimental animal species tested [10]. Consumption of mycotoxincontaminated foods has been associated with several cases of human poisoning, or mycotoxicosis, sometimes resulting in death [3]. AF outbreaks affecting a large geographical area and causing over 123 deaths were reported in Kenya in 2004 and 2005. Epidemiological studies from this case showed a relationship between the outbreak and the local methods of harvesting, storing and preparing maize. Contamination of maize with $\mathrm{AF}$ was found up to $1000 \mathrm{ng} / \mathrm{g}$ [11]. Recently, have demonstrated that consumption of maize is an important source of aflatoxin exposure in young children in West Africa. AF have been found as contaminants in agricultural and food products especially in cereals and cereal products and animal feeds [12-19]. In the European Union, the maximum tolerable levels for AFB1 and total AF in cereals for human consumption are 2 and $4 \mathrm{ng} / \mathrm{g}$, respectively and $20 \mathrm{ng} / \mathrm{g}$ for total AF in poultry feeds [20,21]. Cyclopiazonic acid (CPA) is another toxic secondary metabolite produced by A. flavus [2]. It causes necrosis of liver or gastrointestinal tissue and necrotic changes in skeletal muscle and kidney. However, there are suggestions that the teratogenic potential of CPA is low [22]. Isolates of A. flavus have been reported to coproduce Aflatoxins and CPA, as well as other toxins in different amounts [23]. The present study was carried out to determine Aflatoxins, CPA and their A. flavus isolates production from Egyptian corn.

\section{Materials and Methods}

\section{Survey Samples Study}

Sixty samples $(1 / 2 \mathrm{~kg}$ for corn) of local corn were collected from different markets in Cairo and Giza Governorates during winter and summer season.

\section{Isolation of Fungi Associated With Local Corn}

Fungi associated with corn were isolated according to methods of Lichtwardth, et al. [24,25]. All corn samples were immersed in sodium hypochlorite solution (3\%) as a sterilizer, for 3 minutes, rinsed 3 times in sterile distilled water then dried between sterile filter paper. Isolation of fungi was made by randomly taking 100 disinfested grains from samples of each location and directly plated in 20 Petri-dishes (5 grains per a dish) on Czapek's agar medium, then incubated at $25^{\circ} \mathrm{C}$ for 4 day's. Then, the percentage of the infected grains were determined and the fungal colonies that developed from the infected grains were counted, isolated, purified and maintained on a slant potato dextrose agar (PDA) medium for identification trials. 


\section{Identification of the Fungal Isolates}

All the isolated fungi were identified by studying the cultural characteristics, as well as the microsocial structures on Gzapek's agar medium, according to the procedures of Numbers of the species of Aspergillus were classified according to the key published by Raper and Fennell, while for species of other isolated fungi the "Manual of clinical mycology" by Count, et al. was used [26-29].

\section{Production of AFs and CPA by Isolated A. flavus Strain}

The media used for examining mycotoxin production of the strains were YES medium (2\% yeast extract and $15 \%$ sucrose (Merck) /liter distilled water) YES (Difco) [30].

\section{Preparation of AFs and CPA Standards}

Chemical and reagents: Acetonitrile, acetone, ethanol, diethyl ether, hexane, methanol and chloroform were supplied by Merck (Darmstadt, Germany) HPLC-grade. Stock standard solutions of Aflatoxins with concentrations of $100 \mu \mathrm{g} / \mathrm{ml}$ were prepared in benzeneacetonitrile (98:2, v/v), wrapped in aluminum foil to prevent gradual break down of Aflatoxins under UV light and kept under protected conditions at- $20{ }^{\circ} \mathrm{C}$. All other inorganic chemicals and organic solvents were of reagent grade or higher.

Aflatoxin standard: Preparation of aflatoxin standard was carried out according to the association of Official Analytical Chemists, AOAC [31]. The crystals of Aflatoxins $B_{1}, B_{2}, G_{1}$ and $G_{2}$ were diluted using benzene-acetonitrile (98: $2 \mathrm{v} / \mathrm{v}$ ) to obtain a concentration of 8 to $10 \mu \mathrm{g} / \mathrm{ml}$ (stock solution).

\section{Cyclopiazonic acid standard}

- Stock solution

Pure solid CPA (Sigma) was dissolved in methanol (liquid chromatography grade) at $1 \mathrm{mg} / \mathrm{ml}$ and stored at $0{ }^{\circ} \mathrm{C}$ in the dark.

\section{- Working solution}

Stock solution was diluted with methanol (liquid chromatography grade) with a CPA concentration of 40 , $100,500 \mathrm{ng} / \mathrm{ml}$ and 10, 100, $200 \mu \mathrm{g} / \mathrm{ml}$.

\section{Extraction of both Myctoxins ( AFs \& CPA) According the Method of Gqaleni, et al. [2]}

Sixty samples were extracted in a warring blender with methanol/ dicholoromethan (DCM) (1:1) and blended for $2 \mathrm{~min}$. The mixture was filtered and the filtrate was evaporated to dryness. The residue was partitioned between $200 \mathrm{ml} \mathrm{n}$-hexane and methanol (1:1), the $\mathrm{n}$-hexane layer was discarded and the methanol layer was evaporated to dryness. The residue was partitioned between $200 \mathrm{ml}$ di-chloromethane (DCM) and distilled water (1:1) and the DCM layer was extracted three times with saturated sodium hydrogen carbonate solution (100 $\mathrm{mL}$ ).The (DCM) extract layer was concentrated, and containing aflatoxins, was rotary evaporated and concentrated under a gentle stream of nitrogen. The aqueous layer was carefully acidified to $\mathrm{pH} 2$ (with $0.5 \mathrm{~N}$ hydrochloric acid) and extracted three times with (DCM) $(100 \mathrm{ml})$. The (DCM) extract was concentrated and contained of cyclopiazonic acid.

\section{Derivatization for Aflatoxins}

Added 200ul hexane to residue from dry film and added $50 \mu \mathrm{l}$ Trifluroacetic acid (TFA), cap vial, and their mixed by vortex vigorously for $30 \mathrm{~s}$. Let mixture stand 5 min. By pipet was added $1.950 \mathrm{ml}$ Water- acetonitril $(9$ +1 ) vortex mix vigorously for $30 \mathrm{~s}$, and at let layers separate $10 \mathrm{~min}$. filter through $0.45 \mu \mathrm{m}$ microfilter into 5 ml screw -cap vial for subsequent HPLC analyses AOAC [31].

\section{TLC Plates Aluminium Sheets}

TLC plates aluminium sheets $(20 \times 20 \mathrm{~cm})$ precoated with silica gel G 60 without Fluorescence indicator, No 1.05553, Layer thickness $0.2 \mathrm{~mm}$, were obtained from Merck, 64271 Darmstadt, Germany.

Thin Layer Chromatography (TLC) for Detection and Separation of Myctoxins: The TLC procedure for detection and separation of mcotoxins according to Vaamonde et al. as follow: Mycotoxin (AFs and CPA) detection were performed using thin layer chromatography on silica gel G60 plates with and without oxalic acid impregnation for individual of $\mathrm{CPA}$ and $\mathrm{AFs}$ separation, respectively. For CPA the plates were activated for $2 \mathrm{~h}$ at $110^{\circ} \mathrm{C}$. To produce oxalic acidimpregnated TLC plates, precoated plates were dipped in a $2 \%$ methanolic solution of oxalic acid for $2 \mathrm{~min}$ and air dried overnight. The TLC plates were developed in toluene-Ethylactate- $90 \%$ formic acid $(6: 3: 1, \mathrm{v} / \mathrm{v})$ for Aflatoxins but toluene-ethyl acetate- $90 \%$ formic acid (5:4:1, v/v) for cyclopiazonic acid . CPA in daylight after spraying treatment of the plates with Erlich's reagent $1 \mathrm{~g}$ of 4-dimethylaminobenzaldehyde in $75 \mathrm{ml}$ ethanol and 25 $\mathrm{ml}$ concentrated $\mathrm{HCl}$ ), with subsequent development of blue spots. The plate was dried at room temperature until the excess of solvent disappeared. Aflatoxins were visualized under long wave UV light (366 nm). The suitable concentration used for TLC was $0.5 \mu \mathrm{g} / \mathrm{ml}$ 
aflatoxin $B_{1}$ and $G_{1}$ while that of $B_{2}$ and $G_{2}$ was more diluted (about $0.1 \mu \mathrm{g} / \mathrm{ml}$ ).Dilution was carried out using benzene-acetonitril mixture $(98: 2, \mathrm{v} / \mathrm{v})$ in preparation of TLC .

\section{Determination of AFs A by HPLC}

High performance liquid chromatography (HPLC) was used to Aflatoxins determination. A mobile phase consists of Water: Acetonitril: Methanol (240:120:40) [32,9,33]. The system equipped with ( Waters 600) delivery system . HPLC column a reverse phase analytical column packed with C18 material (Spherisorb $5 \mu \mathrm{m}$ ODS2, $15 \mathrm{~cm} \times 4.6 \mathrm{~nm}$ ). The detection was performed using The fluorescence detector was operated at an excitation wave length of 360 $\mathrm{nm}$ and an emission wave length of $440 \mathrm{~nm}$.The separation was performed at $40^{\circ} \mathrm{C}$ temperature at a flow rate of $1.0 \mathrm{ml} / \mathrm{min}$. Data were integrated and recorded using a Millennium Chromatography Manger Software 2010 (Waters, Milford MA 01757).

\section{Determination of CPA by HPLC}

\section{Mobile phase solvents consists of}

Solvent A: Methanol: water (85:15, v/v)

Solvent B: 0 Methanol: $4 \mathrm{mM}$ zinc sulfate $(85: 15, \mathrm{v} / \mathrm{v})$

Solvent $A$ and $B$ were used in a linear gradient from mobile phase $A$ to mobile phase $B$ in 10 min at a flow rate of $1 \mathrm{ml} / \mathrm{min}$.

\section{Apparatus}

High performance liquid chromatography (HPLC) was used to CPA determination. The system equipped with (Waters 600) delivery system. HPLC column Reverse phase hyper clone $5 \mu$ ODS C18 column $(2.5 \mathrm{mmX} 30 \mathrm{~cm})$; The detection was performed using U.V detector (waters
486) at $279 \mathrm{~nm}$ wavelength, oven temperature $40{ }^{\circ} \mathrm{C}$, using linear program of $25 \mathrm{~min}$ period and $1 \mathrm{ml} / \mathrm{min}$ constant solvent flow rate. Data were integrated and recorded using a Millennium Chromatography Manger Software 2010 (Waters, Milford MA 01757). A calibration curve correlating peak-area and concentration was constructed for quantification purposes, using toxin standards. Confirmation of CPA in the sample was achieved using (UV) detector.

\section{Results and Discussion}

\section{Isolation and Identification of Fungi Associate with Corn.}

Fungi isolation on Czapek's Agar Medium: Data in Table 1 represent the fungi isolated on Czapek's agar medium from corn purchased from retail markets in Cairo and Giza Governorates during the winter and summer seasons, respectively. The results in Table 1 showed that the percentage of fungal infected grains in both seasons winter and summer were $97,100,100$, and $98 \%$ in local corn grains were obtained from retail markets in Cairo and Giza Governorates, respectively. The highest rate of infected was found in corn samples $(100 \%)$ in winter season which stored in shops in Giza Governorate while, in summer season the sample were infected $100 \%$ in corn grains were collected from Cairo Governorate, this may be due to the bad storage conditions in these Governorates. Followed by samples (98\%) from shops in Giza Governorate, while the lowest infection rate was recorded from the corn samples, $(97 \%)$ in the winter season from Cairo Governorate.

\begin{tabular}{|c|c|c|c|c|c|c|c|c|}
\hline $\begin{array}{c}\text { Commodities } \\
\text { Governorates } \\
\text { Seasons }\end{array}$ & $\begin{array}{c}\text { No of } \\
\text { samples }\end{array}$ & $\begin{array}{c}\% \\
\text { Infections }\end{array}$ & $\begin{array}{c}\text { Total } \\
\text { fungal } \\
\text { Counts }\end{array}$ & \multicolumn{5}{|c|}{$\%$ Isolated Fungi } \\
\hline Corn & & & & Aspergilluss & Fusarium & Penicillum & Alternaria & Rhizopus \\
\hline Cairo & & & & & & & & \\
\hline Winter & 30 & 97 & 110 & 52 & 25 & 13 & 10 & - \\
\hline Summer & 30 & 100 & 190 & 63 & 22 & 11 & 4 & - \\
\hline Giza & & & & & & & & \\
\hline Winter & 30 & 100 & 130 & 53 & 15 & 27 & 5 & - \\
\hline Summer & 30 & 98 & 163 & 57 & 17 & 20 & 6 & - \\
\hline
\end{tabular}

Table 1: Fungi isolated of corn samples collected from Cairo and Giza governorates.

Concerning the different fungal genera which were found on and in corn grain, sample the genera of Aspergillus, Penicillium, Fusarium, and Alternaria, were found in all samples were collected from Cairo and Giza
Governorates. However, the Rhizopus genus was not recorded in both seasons in corn grain samples. The frequency of occurrence of Aspergillus, Pencillum, Fusarium, and Alternaria were 50,35.5, 14.5 , and $10 \%$ on 
corn samples in Cairo Governorate in winter season, and it was 63.3,24, 30.69 .0 and $1.2 \%$ during summer season of 2004.However, in the corn samples were collected from Giza governorate were found 53.8, 15.4, 353, and $5.5 \%$, in winter season, while in summer season were found 58.8, $23.8,33.8$, and $6.3 \%$. The results also indicated that the dominant fungi genera were Aspergillus, Fusarium, Penicillium and Alternaria in all corn and peanut samples in both seasons Vaamonde, et al. [34] found that the incidence of Aflatoxigenic A. flavus strains was higher in peanuts $(69 \%)$ than in wheat $(13 \%)$ or soybeans $(5 \%)$ while the ratio of CPA producers A. flavus isolated from all substrates was very high (94\% in peanuts, $93 \%$ in wheat and $73 \%$ in soybeans). Isolates of $A$. flavus able to produce simultaneously Aflatoxins type B and CPA were detected in all substrates, suggesting the possibility of cooccurrence of these toxins.

\section{Natural Occurrence of Mycotoxic Fungi Isolated from Corn}

Mycotoxins are a poison produced by an active growing mold. Molds may be activity growing without Mycotoxin formation. Therefore, this study was carried out to isolate mycotoxic fungi namely A. flavus producing Aflatoxins, and Cyclopiazonic acid. Data in Table 2 indicate that, out of 239 Aspergillus spp. isolates which isolated from corn samples collected from Cairo and Giza Governorates, Concerning the frequency distribution of 98 isolates of $A$. flavus were tested for isolation of $A$. flavus 64.5 producing Aflatoxins isolated from corn. The results indicated that 64.5 of the isolates were A. flavus producing both of Aflatoxins and Cyclopiazonic acid form samples of corn. Regarding A. flavus, considerable variability in their mycotoxin-producing potential was found in concordance with others. The results showed that averages of $9.4 \mathrm{mg}$ Aflatoxins /L of the YES medium were produced by $A$. flavus isolates from corn samples .On the other hand, the results showed that averages of $12.56 \mathrm{mg}$ cyclopiazonc acid /L of the YES medium were produced by A. flavus isolates from corn. Resnik, et al. [35] found that 33 of 34 A. flavus isolates from corn produced CPA and only 5 of these strains produced Aflatoxins $B_{1}$ simultaneously. Cyclopiazonic acid (CPA) has been found as a natural contaminant of corn and peanuts, often occurring together with the discovery of CPA production by $A$. flavus, 54 isolates of $A$. flavus were investigated for production of CPA and Aflatoxins [36]. Isolated 96 strains of Aspergillus Flavus from samples of stored grain [37]. They found that the Five strains produced Cyclopiazonic acid in the range of $0.5-30 \mathrm{mg} / \mathrm{kg}$ and 9 produced Aflatoxins B1 $(0.1-14.8 \mathrm{mg} / \mathrm{kg})$ but none of them produced both Cyclopiazonic acid and Aflatoxins . It was found that 28 of the $54(52 \%)$ produced CPA whereas only $18(33 \%)$ produced Aflatoxins. Isolates of A. flavus have been reported to co-produce Aflatoxins and CPA, as well as other toxins in different amounts. Mphande, et al. screened of 32 isolates for Mycotoxin production of A $[25,38]$. Flavus, were found that 11 did not produce detectable Aflatoxins , 8 produced only Aflatoxins B1 and $B 2$, and 13 produced all four Aflatoxins $B_{1}, B_{2} G_{1}$ and $G_{2}$ ) in varying amounts. Only 6 of the A. flavus isolates produced Cyclopiazonic acid at concentrations ranging from 1 to $55 \mu \mathrm{g} / \mathrm{kg}$. The one A. parasiticus isolate screened also produced all the four Aflatoxins $(1,200 \mu \mathrm{g} / \mathrm{kg})$ but did not produce Cyclopiazonic acid. When the raw peanut samples $(n=120)$ were analyzed for total Aflatoxins, $78 \%$ contained Aflatoxins at concentrations ranging from 12 to $329 \mu \mathrm{g} / \mathrm{kg}$.

\begin{tabular}{|c|c|c|c|c|c|c|c|c|}
\hline Source & $\begin{array}{c}\text { Isolates of } \\
\text { Aspergillus } \\
\text { tested (No.) }\end{array}$ & $\begin{array}{c}\text { Isolates of } \\
\text { Aspergillus } \\
\text { flavus (No.) }\end{array}$ & $\begin{array}{c}\text { Isolates of } \\
\text { A.flavus } \\
\text { producing } \\
\text { Aflatoxins (No.) }\end{array}$ & $\begin{array}{c}\text { Isolates of } \\
\text { A.flavus } \\
\text { producing } \\
\text { Aflatoxins (\%) }\end{array}$ & $\begin{array}{c}\text { Isolates of } \\
\text { A.flavus } \\
\text { producing CPA } \\
\text { (\%) }\end{array}$ & $\begin{array}{c}\text { Cyclopiazonic } \\
\text { acid } \\
\text { concentration } \\
\text { (mg/L) }\end{array}$ & $\begin{array}{c}\text { Total of } \\
\text { Aflatoxins } \\
\text { concentration } \\
\text { (mg/L) }\end{array}$ \\
\hline Corn & 239 & 1520 & 98 & 64.5 & 64.5 & $\begin{array}{c}\text { Range } \\
\text { (mean } \pm \text { SE }\end{array}$ & Range & $\begin{array}{c}\text { Mean } \pm \\
\text { SE }\end{array}$ \\
\hline
\end{tabular}

Table 2: Natural occurrence of Aspergillus flavus isolated from raw corn t samples collected from Cairo and Giza Governorates and its ability for Aflatoxins and cyclopiazonic acid (CPA) production in YES medium.

\section{Natural Co-occurrence of Aflatoxins and Cyclopiazonic Acid (CPA) in Corn}

It is worthy to mention that the current investigation to detect the Aflatoxins $\left(\mathrm{B}_{1}, \mathrm{~B}_{2} \mathrm{G}_{1}\right.$ and $\left.\mathrm{G}_{2}\right)$ and cyclopiazonic acid (CPA) levels and /or frequencies in the Egyptian corn. Hundred and twenty samples of corn $(60$ from Cairo and 60 from Giza Governorates) were collected from retail markets in Cairo and Giza Governorates during winter and summer seasons. The data in Tables $3 \& 4$ showed the natural occurrence of Aflatoxins and cyclopiazonic acid in corn grain samples in the winter and summer season during 2004/2005 
collected from Cairo and Giza Governorates. The results in Table 3 indicated that 9 samples out from $30(30.0 \%)$ of both Aflatoxins ( $\mathrm{B}_{1}$ and $\left.\mathrm{B}_{2}\right), 7 / 30 \quad(23.3 \%)$ of both $\mathrm{AFG}_{1}$ and $\mathrm{CPA}$, and $6 / 60$ (20.0\%) of $\mathrm{AFG}_{2}$ from corn grain samples collected from Cairo Governorate in winter season were contaminated with both of Aflatoxins $\left(\mathrm{AFB}_{1}\right.$, $\mathrm{AFB}_{2}, \mathrm{AFG}_{1}$ and $\left.\mathrm{AFG}_{2}\right)$ and CPA . While in summer season, 11 samples out from 30 (36.3\%) of $\mathrm{AFB}_{1}, 10 / 30$ (20.0\%) $\mathrm{AFB}_{2} 8 / 30$ (26.6) of CPA and of both $\mathrm{AFG}_{1} \mathrm{AFG}_{2} 6$ samples out from 30 were contaminated with both Aflatoxins $\left(\mathrm{AFB}_{1}, \mathrm{AFB}_{2}, \mathrm{AFG}_{1}\right.$ and $\left.\mathrm{AFG}_{2}\right)$ and $\mathrm{CPA}$. The concentrations of both Aflatoxins $\left(\mathrm{AFB}_{1}, \mathrm{AFB}_{2}, \mathrm{AFG}_{1}\right.$ and $\left.\mathrm{AFG}_{2}\right)$ and $\mathrm{CPA}$ were ranged from $(0.02-22.0,0.10-12.0,1.10-12.50$ and $2.20-13.0$ ) and $0.93-35.0 \mu \mathrm{g} / \mathrm{kg}$ in the corn samples were collected from Cairo Governorate in the winter season, while in the summer season were found ranged of concentrations (1.23- 45.5, 1.10 - 19.0, 2.20 -23.0 , 3.010.0 and 2.0-56.0), for Aflatoxins and CPA, respectively.

\begin{tabular}{|c|c|c|c|c|c|c|c|c|c|c|c|c|}
\hline & \multicolumn{12}{|c|}{ Aflatoxins and Cyclopiazonic Acid in Corn Samples } \\
\hline Seasons & \multicolumn{6}{|c|}{ Winter } & \multicolumn{5}{|c|}{ Summer } & \multirow[b]{2}{*}{ CPA } \\
\hline Type of toxins & AFB1 & AFB2 & AFG1 & AFG2 & Total & CPA & AFB1 & AFB2 & AFG1 & AFG2 & \begin{tabular}{|c|} 
Total \\
AFS
\end{tabular} & \\
\hline $\begin{array}{c}\text { Minimum concentration } \\
(\mu \mathrm{g} / \mathrm{kg})\end{array}$ & 0.02 & 0.1 & 1.1 & 2.2 & AFS & 0.93 & 1.23 & 1.1 & 2.2 & 3 & 6.23 & 2 \\
\hline $\begin{array}{c}\text { Maximum concentration } \\
(\mu \mathrm{g} / \mathrm{kg})\end{array}$ & 22 & 12 & 12.5 & 13 & 3.42 & 35 & 45.5 & 19 & 23 & 10 & 78.3 & 56 \\
\hline $\mathrm{Mean}+\mathrm{SE}$ & $18.7 \pm$ & $8.6 \pm$ & $9.7 \pm$ & $9.81 \pm$ & $57 \pm$ & $21.70 \pm$ & $20.52 \pm$ & 10.56 & $11.36 \pm$ & 6.75 & $39.96 \pm$ & $24.06 \pm$ \\
\hline Mean \pm SE & 2.35 & 1.2 & 1.56 & 1.56 & 42.47 & 4.08 & 3.79 & \pm 1.8 & 2.93 & \pm 1.04 & 7.28 & 6.5 \\
\hline Total No. of sample & 30 & 30 & 30 & 30 & 5.65 & 30 & 30 & 30 & 30 & 30 & & 30 \\
\hline No of positive samples & 9 & 9 & 7 & 7 & & 6 & 11 & 10 & 6 & 6 & & 8 \\
\hline$\%$ of positive samples & 30 & 30 & 23.3 & 23.3 & & 20 & 36.6 & 33.3 & 20 & 20 & & 26.6 \\
\hline
\end{tabular}

Table 3: Natural occurrence of Aflatoxins and cyclopiazonic acid in corn samples collected from Cairo Governorate during winter and Summer Seasons.

\begin{tabular}{|c|c|c|c|c|c|c|c|c|c|c|c|c|}
\hline \multirow{3}{*}{\begin{tabular}{|c|} 
Seasons \\
Type of toxins
\end{tabular}} & \multicolumn{12}{|c|}{ Aflatoxins and Cyclopiazonic Acid Concentrations $(\mu \mathrm{g} / \mathrm{kg})$} \\
\hline & \multicolumn{6}{|c|}{ Winter } & \multicolumn{6}{|c|}{ Summer } \\
\hline & AFB1 & AFB2 & AFG1 & AFG2 & Total AFS & CPA & AFB1 & AFB2 & AFG1 & AFG2 & $\begin{array}{c}\text { Total } \\
\text { AFS }\end{array}$ & CPA \\
\hline Min & 2.23 & 1.1 & 2.2 & 1 & 6.53 & 2 & $\overline{93}$ & 2.1 & 1.2 & 2 & 6.23 & 2.7 \\
\hline Maximum & 30.5 & 17 & 14 & 13 & 60 & 51 & 35.5 & 17 & 20 & 18 & 75 & 46 \\
\hline Mean \pm SE & $\begin{array}{c}19.67 \pm \\
3.21 \\
\end{array}$ & $\begin{array}{c}10.37 \pm \\
2.04\end{array}$ & $\begin{array}{c}9.53 \pm \\
1.67\end{array}$ & $\begin{array}{c}8.87 \pm \\
1.97\end{array}$ & $\begin{array}{c}54.47 \pm \\
7.12 \\
\end{array}$ & $\begin{array}{r}25.3 \pm \\
6.7 \\
\end{array}$ & $\begin{array}{c}20.19 \pm \\
2.96\end{array}$ & $\begin{array}{c}11.23 \pm \\
1.93 \\
\end{array}$ & $\begin{array}{c}11.9 \pm \\
2.67\end{array}$ & $\begin{array}{c}9.64 \pm \\
2.25\end{array}$ & $\begin{array}{c}46.49 \pm \\
7.47\end{array}$ & $\begin{array}{c}23.17 \pm \\
5.15\end{array}$ \\
\hline $\begin{array}{l}\text { Total No. of } \\
\text { sample }\end{array}$ & 30 & 30 & 30 & 30 & & 30 & 30 & 30 & 30 & 30 & & 30 \\
\hline
\end{tabular}

Table 4: Natural occurrence of Aflatoxins and cyclopiazonic acid in corn sample collected from Giza Governorate during winter and summer seasons.

The results in Table 4 show the natural occurrence of Aflatoxins and cyclopiazonic acid in corn grain samples in the winter and summer seasons collected from Giza Governorate. The results indicated that 7 samples out from $30(23.3 \%)$ of each aflatoxin $\left(B_{1}, B_{2}\right)$ while, $6 / 30(20$ $\%$ ) of each $\mathrm{AFG}_{1}, \mathrm{AFG}_{2}$ and $\mathrm{CPA}$ were contaminated with Aflatoxins $\left(\mathrm{AFB}_{1}, \mathrm{AFB}_{2}, \mathrm{AFG}_{1}\right.$ and $\left.\mathrm{AFG}_{2}\right)$ and $\mathrm{CPA}$ respectively in winter season from corn samples collected from Giza Governorate. On the other hand, 10 samples out from $30(33.3 \%)$ of each aflatoxin $\left(\mathrm{AFB}_{1}\right.$ and $\left.\mathrm{B}_{2}\right)$ and $7 / 30(23.3 \%)$ of both $\mathrm{AFG}_{1}$ and $\mathrm{AFG}_{2}$ and $10 / 30(33.3 \%)$ of CPA were contaminated with aflatoxin $\left(\mathrm{AFB}_{1}, \mathrm{AFB}_{2}\right.$, $\mathrm{AFG}_{1}$ and $\mathrm{AFG}_{2}$ ) and $\mathrm{CPA}$ in the Giza Governorate, in summer season respectively. This represent $23.3 \%$ and $33.3 \%$ aflatoxin $\left(\mathrm{AFB}_{1}\right)$ positive samples for corn grain samples collected from Giza Governorate in both season. The concentration of both aflatoxin $\left(\mathrm{AFB}_{1}, \mathrm{AFB}_{2}, \mathrm{AFG}_{1}\right.$ and $\left.\mathrm{AFG}_{2}\right)$ and CPA were ranged from $(2.23-30.5,1.10-17.0$, $2.20-14.0$, and $1.0-13$ ) and $2.0-51.0 \mu \mathrm{g} / \mathrm{kg}$ in the corn samples, in the winter season, whereas in the summer season the concentrations of both Aflatoxins $\left(\mathrm{AFB}_{1}, \mathrm{AFB}_{2}\right.$, $\mathrm{AFG}_{1}$ and $\mathrm{AFG}_{2}$ ) and $\mathrm{CPA}$ were ranged from (0.93-35.5, $2.10-17.0,1.20-20.0$ and $2.0-18.0$ ) and $2.7-46.0 \mu \mathrm{g} / \mathrm{kg}$, for Aflatoxins and CPA, respectively. In a survey of peanut products in North America, 19\% of 1416 samples examined were contaminated with an average level of 1 
$\mu \mathrm{g} / \mathrm{kg} \mathrm{AFB}_{1}$ [39]. In Thailand $49 \%$ of 216 samples contained AFB1 at an average level of $424 \mu \mathrm{g} / \mathrm{kg}$ [40]. In parts of India $100 \%$ of maize samples have been found contaminated with aflatoxin in the range of 6,250-15,600 $\mathrm{ig} / \mathrm{kg}$ [41]. Aflatoxins are present in food chain Consumption of aflatoxin in many parts of the world varies from 0 to $30000 \mathrm{ng} / \mathrm{kg} /$ day [42]. The factors such as high temperature and low moisture can result in cracks in the seed and subsequent invasion by the fungus. Temperature and moisture are the dominant factors that affect aflatoxin contamination of corn. Environmental conditions most favorable for maximum growth and aflatoxin production by A. flavus are temperatures greater than $30^{\circ} \mathrm{C}$, maximum relative humidity of greater than $85 \%$, and water activity of 0.98 to 0.99 [43]. Thus, $A$ flavus can infect with proper moisture/temperature conditions during storage almost any stored product [44]. Regional differences in aflatoxin contamination of crops may be attributable to climatic conditions and to agricultural practices that increase susceptibility of plants to invasion by A. flavus [45]. Aflatoxin formation in groundnut is favored by prolonged end of season drought and associated elevated temperature [46].

In general, the TLC technique is simple and does not require special equipment, but most of the published methods suffer from the excessive time needed for analysis and / or inaccuracy of the obtained results. It had been shown previously that spray reagents may lead to variable results because the intensity of fluorescent color is dependent on many difficult-to-control factors such as time, amount of reagent applied to the sample spot, and development of background color.

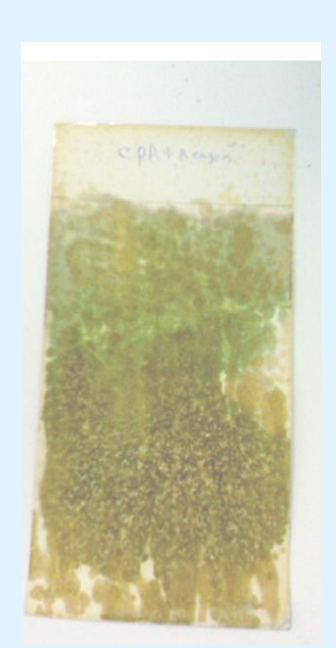

Figure 1: Thin Layer Chromatography of Cyclopiazonic Acid Standard separation by used direct spraying of the apparel Ehrlich's reagent.
It had been shown that the CPA detection by the direct spraying of the apparel (Figure 1) Ehrlich's reagent on the separated CPA spots using the TLC technique resulted in a weak-unstable developed color intensity giving unobvious detection and inaccurate quantitative determination by densitometric procedure.

Thereupon, the current study try to resolve this problem by modification a novel incubating the CPA spots detection with indirect apparel color reagent which giving stable spots color an obvious detection and an accurate quantitative determination by using the densitometric procedure, as shown in the Figure 2.

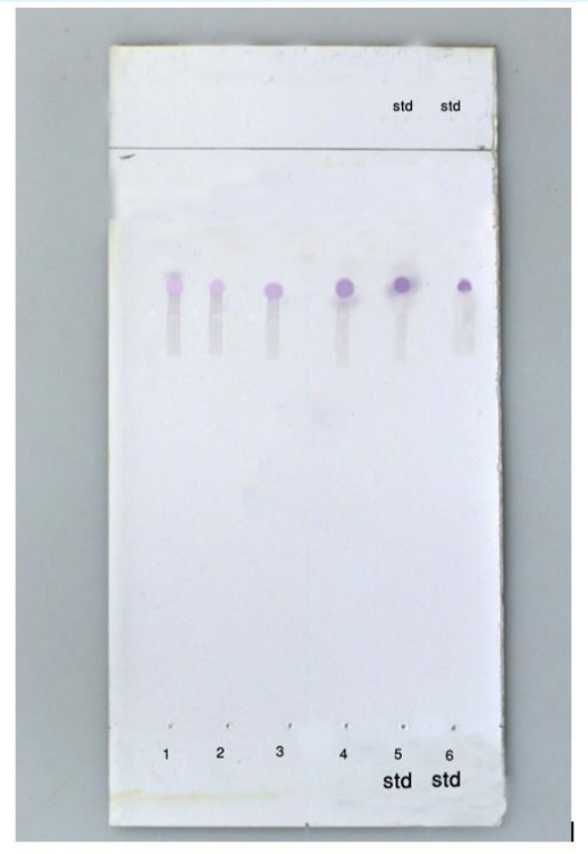

1,2,3,4 = Random samples of corn ,and spot of 5; 6 standard of CPA.

Figure 2: Thin Layer Chromatography of Cyclopiazonic Acid separation of samples and standard by the new method of indirect apparel Ehrlich's reagent.

In this technique, covered surface of TLC plate free of CPA was sprayed with an apparel Ehrlich's reagent and dried. Then, it adhered together to the other covered surface of the other TLC plate on which the spotting of CPA in the tested sample extract or the CPA standard solution was developed in toluene-Ethylactate- $90 \%$ formic acid $(6: 3: 1, \mathrm{v} / \mathrm{v})$ and incubated 2 hours at $35^{\circ} \mathrm{C}$ to give a purple spots in Figure 2. 

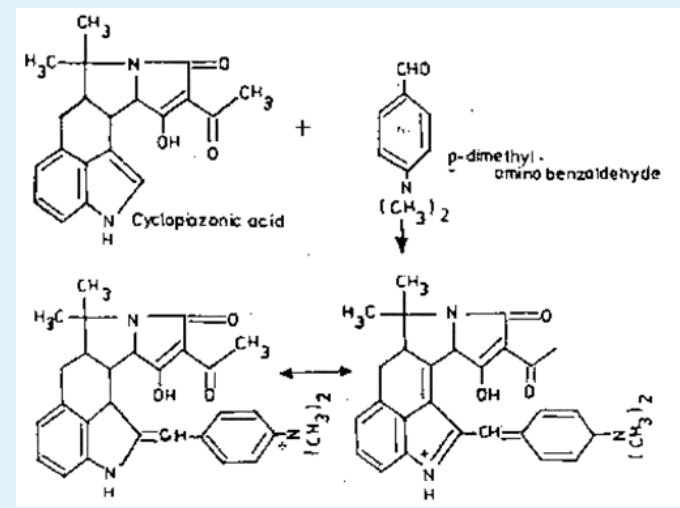

Figure 3: Color reaction of Cyclopiazonic Acid with $\rho$ di-methyl amino benzaldehyde [46].

The color reaction of Erlich's reagent $(\rho-$ dimethylaminobenzaldehyde) with the indol group present in the CPA structure. The reagent $\rho$ dimethylaminobenzaldehyde reacts with $\alpha, \beta$-unsaturated indoles, preferentially in the $\beta$-position, in presence of $\mathrm{HCl}$ to give colored cations, the condensation may be taking place at the $\alpha$-position to give a purple cation, as illustrated in Figure 3.

\section{References}

1. Gourama H, Bullerman LB (1995) Antimycotic and antiaflatoxigenic effect of lactic acid bacteria-a review. Journal of Food Protection 58(11): 12751280.

2. Gqaleni N, Smith JE, Lacey J (1996) Co-production of Aflatoxins and cyclopiazonic acid in isolates of Aspergillus flavus. Food Addit Contam 13(6): 677685.

3. Bathnagar D, Garcia S (2001) Aspergillus. In: Labbe RG, et al. (Eds.), Guide to Foodborne Pathogens. John Wiley and Sons, New York, pp: 35-49.

4. Gonzalez HHL, Resnik SL, Boca RT, Marasas WFO (1995) Mycoflora of Argentinian corn harvested in the main production area in 1990. Mycopathologia 130(1): 29-36.

5. Farr DF, Billis GF, Chamuris GP, Rossman AY (1989) Fungi on plans and plant products in the United States. American Phytopathological Society Press St Paul MN pp: 1-152.

6. Vardon PJ (2003) Mycotoxins: risks in plant, animal and human systems, potential economic costs of mycotoxins in the United State. Cast Task Force pp: 136-142.

7. Goodman M (1995) Maize. In: Smartt J, (Eds.), The Evolution of Crop Plants. John Wiley and Sons, New York, pp: 193-202.

8. Ellis WO, Smith JP, Simpson BK, Oldman JH (1991) Aflatoxins in food: occurrence, biosynthesis, effects on organisms, detection and methods of control. Crit Rev Food Sci Nutr 30(4): 403-439.

9. Deabes MM, Darwish HR, Abdel-Aziz KB, Farag IM, Nada SA, et al. (2012) Protective effects of Lactobacillus rhamnosus GG on Aflatoxins -induced Toxicities in male Albino Mice. J Environmental \& Analytical Toxicology 2(3): 2-9.

10. Gradelet S, Astorg P, Le AM, Berges R, Suschetet M (1997) Modulation of aflatoxin B1 carcinogenicity, genotoxicity and metabolism in rat liver by dietary carotenoids: evidence for a protective effect of CYP1A inducers. Cancer Letters 114(1-2): 221-223.

11. CDC (2004) Centers for Disease Control and Prevention. Outbreak of Aflatoxins poisoning-eastern and central provinces, Kenya, January-July 2004. MMWR. Morbidity and Mortality Weekly Report 53(34): 790-793.

12. Abbas HK, Cartwrihgt RD, Wie W, Shier WT (2006) Aflatoxin and fumonisin contamination of corn (maize, Zea mays) hybrids in Arkansas. Crop Protection 25(1): 1-9.

13. Bankole SA, Mabekoje OO (2004) Occurrence of Aflatoxins and fumonisins in pre-harvest maize from south-western Nigeria. Food Addit Contam 21(3): 251-255.

14. Blesa J, Soriano JM, Moltó JC, Mañes J (2004) Limited survey for the presence of Aflatoxins in foods from local markets and supermarkets in Valencia, Spain. Food Addit Contam 21(2): 165-171.

15. Pietri A, Bertuzzi T, Pallaroni L, Piva G (2004) Occurrence of mycotoxins and ergosterol in maize harvested over 5 years in northern Italy. Food Addit Contam 21(5): 479-487.

16. Dalcero A, Magnoli C, Luna M, Ancasi G, Reynoso MM, et al. (1998) Mycoflora and ;naturally occurring mycotoxins in poultry feeds in Argentina. Mycopathologia 141(1): 37-43. 


\section{Advances in Clinical Toxicology}

17. Sassahara M, Pontes Netto D, Yanaka EK (2005) Aflatoxin ccurrence in foodstuff supplied to dairy cattle and Aflatoxin M1 in raw milk in the North of Paraná state. Food Chem Toxicol 43(6): 981-984.

18. Schweitzer SH, Ouist CF, Grimes GL, Forest DL (2001) Aflatoxin levels in corn available as wild turkey feed in Georgia. J Wild Dis 37(3): 657-659.

19. Vlachou S, Zoiopoulos PE, Drosinos EH (2004) Assessment of some hygienic parameters of animal feeds in Greece. Animal Feed Science and Technology 117(3-4): 331-337.

20. European Commission (1998) Commission Regulation (EC) No. 1525/98 of July 1998, amending Regulation (EC)194/97 of 31 January 1997 setting maximum levels for certain contaminants in foodstuffs. Official Journal of the European Communities L 201: 43-46.

21. FAO (1995) Edible nuts. Non-wood forest products. No. 5. Food and Agriculture Organization of the United Nations, Rome.

22. Morrisey RE, Cole RJ, Dorner JW (1984) The effects of cyclopiazonic acid on pregnant and fetal development of Fischer rats. J Toxicol Environ Health 14(4): 585594.

23. Martins ML, Martins HM (1999) Natural and in vitro coproduction of cyclopiazonic acid and Aflatoxins . Journal of Food Protection 62(3): 292-294.

24. Lichtwardth RW, Basrn GL, TiffangLH (1958) Fungus growth in shelled corn as affected by moisture. J Agr Res 56: 291-307.

25. Ichinoe ME, Kurata HA, Sugtura YB, Uemo YS (1983) Chemotaxonomy of Gibberella zea with special reference to production of trichothecenes and zeralenone. Applied and Environmental Microbiology 46(6): 1364-1369.

26. Gilman JE (1957) "A manual of soil fungi" low state college press, Anes, Iowa USA pp: 392.

27. Barnnett HL, Hunter BB (1972) Illustration genera of imperfect fungi. Burgess Publishing Company, MinnEapolis 15 min USA pp: 225.

28. Raper JP, Fennell DT (1965) The genus Aspergillus williams and Wilkins. Baltimorr, USA.
29. Count NF, Martin FS, Smith DT, Baker RF, Gallaway JL (1954) Manual of clinical mycology, WB Saunders Company, Philadelphia.

30. Singh K, Frisbad JC, Thrane U, Mathur SB (1991) An illustrated manual on identification of some seedborne Aspergilli, Fusaria, Penicillia and their mycotoxins. Danish government. Insitute of Seed Pathology for Developing Countries. Hellerup pp: 812.

31. H William (2000) AOAC Official methods of analysis of the Association of Analytical Chemists, 17 th (Edn.), Vol 4, Association of Official Analytical Chemists, Arlington VA.

32. Deabes MM, Aboelsoud NH, Taha L (2011) In vitro Inhibition of growth and aflatoxin $\mathrm{B} 1$ production of Aspergillus flavus strain (ATCC 16872) by various medicinal plant essential oils. Macedonian J Medical Sciences 4(4): 345-350.

33. Deabes MM, Wagdy KB, Attallah KAG, El-Desouky TA, Khayria Naguib (2018) Impact of silver Nanoparticles on gene expression in Aspergillus flavus producer aflatoxin B1.Open Access Macedonian Journal of Medical Sciences 6(4): 600-605.

34. Vaamonde G, Patriarca A, Fernandez Pinto V, Comerio R, Degrossi C (2003) Variability of aflatoxin and cyclopiazonic acid production by Aspergillus section flavi from different substrates in Argentina. Int J Food Microbiol 88(1): 79-84.

35. Resnik SL, Gonzalez HHL, Pacin AM, Viora M, Caballero GM, et al. (1996) Cyclopiazonic acid and Aflatoxins production by Aspergillus flavus isolated from Argentinian corn. Mycotoxin Res 12(2): 61-66.

36. Gallagher RT, Latch SM (1977) Production of the termorgenic mycotoxin verruelulogen and fumitremorgin B by Penicillium piscarium Westling. Applied and Environmental Microbiology 33(3): 730731.

37. Cvetnic Z, Pepeljnjak S (1998) Production of cyclopiazonic acid by aflatoxigenic and nonaflatoxigenic strains of Aspergillus flavus. Nahrung 42(5): 321-323.

38. Mphande FA, SiameBA, TaylorJE (2004) Fungi, Aflatoxins, and cyclopiazonic acid associated with peanut retailing in Botswana. J Food Prot 67(1): 96102. 
39. Stoloff L (1977) Aflatoxins - an overview. In Mycotoxins in Human and Animal Health (Eds.), Rodricks JV, et al. Park Forest South, Illinois: Pathotos Publishers pp: 7-28.

40. Shank RC, Gordon JE Wogan GN, Nondasuta A, Subhamani B (1972) Dietary Aflatoxins and human liver cancer. III Field survey of rural Thai families for ingested Aflatoxins. Food Cosmet Toxicol 10(1): 7184.

41. Krishnamachari KAVR, Bhat RV, Nagarajan V, Tilak TBG (1975) Investigations into an outbreak of hepatitis in parts of Western India. Indian J med Res 63: 1036-1048.

42. Denning DW (1987) Aflatoxin and human diseases, In Davies DM, et al. (Eds.), Adverse drug reactions and acute poisoning reviews, Oxford University Press, Oxford, United Kingdom 4: 175-209.
43. Payne GA, Hagler WM, Adkins CR (1988) Aflatoxin accumulation in inoculated ears of field-grown maize. Plant Dis 72: 422-424.

44. Payne GA (1992) Aflatoxin in maize. Crit Rev Plant Sci 10(5): 423-440.

45. Pildaina MB, Vaamonde G, Cabral D (2004) Analysis of population structure of Aspergillus flavus from peanut based on vegetative compatibility, geographic origin, mycotoxin and sclerotia production. Int J Food Microbiol 93(1): 31-40.

46. Rachaputi NR, Wright GC, Kroschi S (2002) Management practices to minimise pre-harvest aflatoxin contamination in Australian groundnuts. Austr J Exp Agric 42(5): 595-605.

47. Rathinavelu A, Shanmugasundaram ER (1984) Simple colorimetric estimation of cyclopiazonic acid in contaminated food and feeds. J Assoc off Anal Chem 67(1): 38-40.

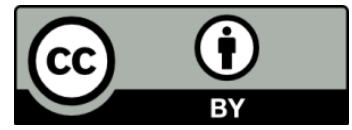

